\title{
Evaluation of anthropogenic secondary organic aerosol tracers from aromatic hydrocarbons
}

\author{
Ibrahim M. Al-Naiema and Elizabeth A. Stone \\ Department of Chemistry, University of Iowa, Iowa City, IA 52242, USA \\ Correspondence to: Elizabeth A. Stone (betsy-stone@uiowa.edu)
}

Received: 8 September 2016 - Discussion started: 13 September 2016

Revised: 21 December 2016 - Accepted: 7 January 2017 - Published: 10 February 2017

\begin{abstract}
Products of secondary organic aerosol (SOA) from aromatic volatile organic compounds (VOCs) 2,3-dihydroxy-4-oxopentanoic acid, dicarboxylic acids, nitromonoaromatics, and furandiones - were evaluated for their potential to serve as anthropogenic SOA tracers with respect to their (1) ambient concentrations and detectability in $\mathrm{PM}_{2.5}$ in Iowa City, IA, USA; (2) gas-particle partitioning behaviour; and (3) source specificity by way of correlations with primary and secondary source tracers and literature review. A widely used tracer for toluene-derived SOA, 2,3-dihydroxy-4-oxopentanoic acid was only detected in the particle phase $\left(F_{\mathrm{p}}=1\right)$ at low but consistently measurable ambient concentrations (averaging $0.3 \mathrm{ng} \mathrm{m}^{-3}$ ). Four aromatic dicarboxylic acids were detected at relatively higher concentrations $\left(9.1-34.5 \mathrm{ng} \mathrm{m}^{-3}\right)$, of which phthalic acid was the most abundant. Phthalic acid had a low particlephase fraction $\left(F_{\mathrm{p}}=0.26\right)$ likely due to quantitation interferences from phthalic anhydride, while 4-methylphthalic acid was predominantly in the particle phase $\left(F_{\mathrm{p}}=0.82\right)$. Phthalic acid and 4-methylphthalic acid were both highly correlated with 2,3-dihydroxy-4-oxopentanoic acid $\left(r_{\mathrm{s}}=\right.$ $0.73, p=0.003 ; r_{\mathrm{S}}=0.80, p<0.001$, respectively), suggesting that they were derived from aromatic VOCs. Isophthalic and terephthalic acids, however, were detected only in the particle phase $\left(F_{\mathrm{p}}=1\right)$, and correlations suggested association with primary emission sources. Nitromonoaromatics were dominated by particle-phase concentrations of 4-nitrocatechol $\left(1.6 \mathrm{ng} \mathrm{m}^{-3}\right)$ and 4-methyl-5-nitrocatechol (1.6 $\mathrm{ng} \mathrm{m}^{-3}$ ) that were associated with biomass burning. Meanwhile, 4-hydroxy-3-nitrobenzyl alcohol was detected in a lower concentration $\left(0.06 \mathrm{ng} \mathrm{m}^{-3}\right)$ in the particle phase only $\left(F_{\mathrm{p}}=1\right)$ and is known as a product of toluene photooxidation. Furandiones in the atmosphere have only been
\end{abstract}

attributed to the photooxidation of aromatic hydrocarbons; however the substantial partitioning toward the gas phase $\left(F_{\mathrm{p}} \leq 0.16\right)$ and their water sensitivity limit their application as tracers. The outcome of this study is the demonstration that 2,3-dihydroxy-4-oxopentanoic acid, phthalic acid, 4-methylphthalic acid, and 4-hydroxy-3-nitrobenzyl alcohol are good candidates for tracing SOA from aromatic VOCs.

\section{Introduction}

Secondary organic aerosol (SOA) accounts for a large but undefined fraction of organic matter in $\mathrm{PM}_{2.5}$, forming through the photooxidation of biogenic and anthropogenic volatile organic compounds (VOCs) in the gas phase yielding lowvapour-pressure products that partition into the particle phase (Kroll and Seinfeld, 2008; Hallquist et al., 2009). The global fluxes of anthropogenic SOA are poorly constrained and highly uncertain, with a wide range of estimates from 2 to $25 \mathrm{Tg} \mathrm{yr}^{-1}$ (Volkamer et al., 2006; Henze et al., 2008). Measurements suggest that anthropogenic precursors form more SOA than predicted by models (Heald et al., 2005; Volkamer et al., 2006; Matsui et al., 2009), likely due to incomplete model representation of SOA formation pathways (Henze et al., 2008), partitioning (Donahue et al., 2006), ambient conditions ( $\mathrm{Ng}$ et al., 2007), and precursors (Robinson et al., 2007; Fu et al., 2008).

A tracer-based approach has been useful in identifying aerosol sources and source apportionment (Schauer et al., 1996). SOA can be linked to its precursor VOC following the SOA tracer approach introduced by Kleindienst et al. (2007) in which ambient concentration of tracers (or the sum of thereof) are converted to secondary organic carbon 
(SOC) or SOA mass yields using tracer-to-OC or tracer-toSOA ratios, respectively, that were determined in chamber studies. For biogenic SOA, relatively well defined and established tracers are employed, such as methyltetrols for isoprene and $\beta$-caryophyllinic acid for $\beta$-caryophyllene (Kleindienst et al., 2007). In contrast, the tracer-based approach for aromatic SOA relies on a single molecule (2,3-dihydroxy-4oxopentanoic acid (DHOPA)) that is derived from toluene (Kleindienst et al., 2007). Advancing the tracer-based approach to anthropogenic SOA apportionment should involve expanding the number of available tracers, particularly those that form from aromatic VOCs other than toluene.

Chamber experiments have been conducted to identify SOA products formed during the photooxidation of aromatic precursors associated with anthropogenic sources, such as benzene, toluene, ethylbenzene, xylenes (BTEX), and lowmolecular-weight polycyclic aromatic hydrocarbons (PAHs). Furandiones have been identified as a major product of aromatic VOC photooxidation in the presence of $\mathrm{NO}_{x}$ (Bandow et al., 1985; Forstner et al., 1997; Hamilton et al., 2003; Koehler et al., 2004). Nitromonoaromatics (e.g. nitrophenols, methyl-nitrophenols, nitrocatechols, and nitrosalicylic acids) are likewise products of aromatic VOC photooxidation in the presence of $\mathrm{NO}_{x}$ (Forstner et al., 1997; Jang and Kamens, 2001; Hamilton et al., 2005; Sato et al., 2012; Irei et al., 2015), but some of these species have also been detected in the primary emission from vehicles (Tremp et al., 1993) and biomass burning (Iinuma et al., 2010). While nitromonoaromatics have been quantified in ambient aerosol (Dron et al., 2008; Kitanovski et al., 2012; Kahnt et al., 2013), the extent of their formation from primary and/or secondary sources has yet to be determined. Phthalic acid is a product of naphthalene photooxidation (Kautzman et al., 2010) and has been proposed as a tracer for naphthalene and methylnaphthalenes in $\mathrm{PM}_{2.5}$ (Kleindienst et al., 2012). However, phthalic acid has also been observed in the emission of motor exhaust (Kawamura and Kaplan, 1987), and thus both primary and secondary sources can contribute to its ambient concentration. These three classes of compounds can be potentially used a tracers for SOA; however, further ambient studies are needed to evaluate their detectability, ambient concentrations, and origins.

There are many desired characteristics for a molecule to be used as a source tracer. First, it should be unique to the source of origin. For example DHOPA was previously identified as a unique product of toluene photooxidation in the presence of $\mathrm{NO}_{x}$ (Kleindienst et al., 2004), and methyltetrols are unique to isoprene (Claeys et al., 2004a). Second, the tracer should be formed in reasonably high yields so it has sufficiently high concentrations in the atmosphere to allow for reliable quantification. Third, the tracer needs to be reasonably stable in the atmosphere, so that it is conserved between formation and collection at a receptor location. Fourth, an efficient SOA tracer should have a low vapour pressure so that it primarily partitioned to the particle phase, which min- imizes possible underestimation from loss to the gas phase. Thus, an effective SOA tracer will exhibit source specificity, consistent detectability, atmospheric stability, and partitioning to the aerosol phase.

In this work, we examine and evaluate the efficacy of nitromonoaromatics, furandiones, and aromatic dicarboxylic acid isomers as potential SOA tracers in terms of their ambient concentration, gas-particle partitioning, and source specificity through correlations with established tracers, including levoglucosan for biomass burning (Simoneit et al., 1999), hopanes for vehicular emissions (Schauer et al., 1999), and DHOPA for anthropogenic SOA (Kleindienst et al., 2004). Sample preparation procedures were optimized for the simultaneous extraction of primary and potential secondary source tracers, which were then quantified by gas chromatography-mass spectrometry (GC-MS). These methods were applied to measure the ambient concentrations and gas-particle distributions for analytes in fine particulate matter $\left(\mathrm{PM}_{2.5}\right)$ collected in Iowa City, IA, in the autumn of 2015. November was chosen for this study because, in a prior study at this site, biogenic SOA tracers were detected in this month (Jayarathne et al., 2016) and aromatic SOA tracers have a less pronounced seasonal variation than those that are biogenic (Shen et al., 2015; Ding et al., 2012; Lewandowski et al., 2008). Developing and evaluating these tracers provide additional tools for better understanding the contribution of aromatic VOCs to ambient aerosol and will help to expand the current knowledge about the composition and sources of ambient aerosol, particularly in urban and peri-urban environments.

\section{Experimental methods}

\subsection{Field sampling}

Gas and particle $\left(\mathrm{PM}_{2.5}\right)$ samples were simultaneously collected daily for the period 4-15 November 2015 in Iowa City, IA, USA $\left(41.6572^{\circ} \mathrm{N}, 91.5035^{\circ} \mathrm{W}\right)$. The sampler was installed on a wooden platform, and the inlet was positioned $3.5 \mathrm{~m}$ above ground level. The sampling site was surrounded by an agricultural field and a university parking lot. Sample collection was preformed using a medium-volume URG air sampler (3000B, URG Corp.) with a cyclone (URG) operating at a flow rate of $90 \mathrm{~L} \mathrm{~min}^{-1}$. Air flow rate was monitored before and after sampling using a rotameter (Gilmont Instruments). $\mathrm{PM}_{2.5}$ samples were collected on $90 \mathrm{~mm}$ quartz fibre filters (QFF; Pallflex ${ }^{\circledR}$ Tissuquartz $^{\text {TM }}$, Pall Life Sciences) that were pre-cleaned by baking for $18 \mathrm{~h}$ at $550^{\circ} \mathrm{C}$. Gas samples were collected on $52 \mathrm{~mm}$ polyurethane foam (PUF) plugs placed after the filter holder (URG-2000-30-52PC). PUF plugs were pre-cleaned using acetone (HPLC grade, Sigma-Aldrich), hexanes, and acetonitrile (Optima-Fisher Scientific-Fisher Chemical) by a repeated compression extraction apparatus adapted from Rogge et al. (2011). This 
apparatus is composed of a thick-walled borosilicate glass cylinder equipped with a polytetrafluoroethylene (PTFE) valve and PTFE plunger that was used to compress the solvent out of the PUF.

Samples were collected for $23 \mathrm{~h}$, and filter changing was performed at 08:00 (local time). After sampling, filters were transferred to Petri dishes, lined with pre-baked aluminum foil, and sealed with Teflon tape. PUF samples were transferred to pre-baked wide-mouth glass jars, capped with a Teflon-lined cap, and sealed with Teflon tape. Sampled filters and PUF were transported to the laboratory and stored frozen at $-20^{\circ} \mathrm{C}$ until analysis. One field blank was collected for every five samples following the same described procedure, except no air was pulled through the system.

\subsection{Extraction}

All glassware used in this experiment was first baked $\left(500{ }^{\circ} \mathrm{C}\right.$ for $5 \mathrm{~h}$ ) to remove organic contaminants and then silanized (using 5\% solution of dichlorodimethylsilane in toluene) to minimize the sorption of analytes to the glass surface ( $\mathrm{Ki}$ tanovski et al., 2012). Filters and PUF were spiked with isotopically labelled internal standards, representing the different classes of organic compounds reported in this study. Adding internal standards prior to extraction corrects for loss of analyte during the extraction process, provided the internal standard adequately represents the chemical and physical properties of the analyte. Specifically, internal standards and their corresponding analytes were 3-nitrosalicylic acid-D 3 and 5-nitrosalicylic acid; 4-nitrophenol (4NP)-D 4 and other nitromonoaromatics; maleic anhydride- $\mathrm{D}_{2}$ for 2,5 furandione, and succinic anhydride-2,2,3,3- $\mathrm{D}_{4}$ for the three other furandiones; levoglucosan ${ }^{13} \mathrm{C}_{6}$ for levoglucosan; ketopinic acid (KPA) for DHOPA; phthalic acid-D 4 for aromatic dicarboxylic acids; and acenaphthene- $\mathrm{D}_{10}$, pyrene$\mathrm{D}_{10}$, benzo[a]anthracene- $\mathrm{D}_{12}$, coronene- $\mathrm{D}_{12}$ for PAHs. The use of KPA as an internal standard for DHOPA builds upon prior work by Kleindienst et al. (2007).

Filters were extracted sequentially with three $10 \mathrm{~mL}$ portions of acetonitrile using ultrasonication (Branson 5510, 137 $\mathrm{W})$ for $15 \mathrm{~min}$ at 60 sonics per minute. The combined three extracts were reduced to $2 \mathrm{~mL}$ by rotary evaporation at $30^{\circ} \mathrm{C}$, $120 \mathrm{rpm}$, and $200 \mathrm{mbar}$. The reduced extracts were filtered with a $0.25 \mu \mathrm{m}$ PTFE syringe filters and stored frozen at $-20^{\circ} \mathrm{C}$ until analysis. Immediately prior to analysis, the extracts were evaporated to $100 \mu \mathrm{L}$ under a gentle stream of ultra-pure nitrogen at $30^{\circ} \mathrm{C}$. PUF samples were extracted by three cycles of repeated compression using acetonitrile; extracts were then combined, evaporated, filtered, and reduced to the final volume using the same conditions as filter extracts.

\subsection{Instrumental analysis}

OC and elemental carbon (EC) were measured by thermaloptical analysis (Sunset Laboratory Inc.) on a $1 \mathrm{~cm}^{2}$ filter portion, following Schauer et al. (2003).

Organic species were analysed using an Agilent 7890A GC, coupled with 5975C MS (Agilent Technologies). 2,3Dihydroxy-4-oxopentanoic acid (Toronto Research Chemicals), phthalic acid isomers, levoglucosan, and biogenic SOA tracers were trimethylsilylated with $\mathrm{N}, \mathrm{O}$ bis(trimethylsilyl)trifluoroacetamide (BSTFA-TMCS; Fluka Analytical $99 \%$ ) prior to analysis. The silylation reaction was performed by evaporating $10 \mu \mathrm{L}$ of the extract under a gentle stream of nitrogen to dryness, adding $20 \mu \mathrm{L}$ of the silylation agent and $10 \mu \mathrm{L}$ of pyridine (Burdick \& Jackson, Anhydrous), and heating to $70^{\circ} \mathrm{C}$ for $3 \mathrm{~h}$. A $2 \mu \mathrm{L}$ aliquot of the silanized extract was introduced to the GC-MS equipped with a DB-5 column, electron ionization (EI) source $(70 \mathrm{eV})$, and a GC inlet temperature of $300^{\circ} \mathrm{C}$. Nitromonoaromatics were also silylated using the same reagent but under different conditions, in which $20 \mu \mathrm{L}$ of the extract was evaporated to dryness under a gentle stream of nitrogen, $10 \mu \mathrm{L}$ of the silylation agent was added, and then the mixture was capped and heated for $90 \mathrm{~min}$ at $100^{\circ} \mathrm{C}$. The different silylation protocol used for nitromonoaromatics yielded more symmetrical peak shapes and higher intensities than the derivatization method used for levoglucosan and phthalic acid isomers that resulted in asymmetrical nitromonoaromatic peaks with low intensities. The GC injection volume was $1 \mu \mathrm{L}$, and the inlet conditions, column type, and MS parameters matched those previously described. Furandiones were analysed using the method developed in our previous work (Al-Naiema et al., 2017), and PAHs were analysed using a DB-5 column as described elsewhere (Al-Naiema et al., 2015).

Responses of the analytes were normalized to the corresponding isotopically labelled internal standards and quantified using a linear calibration curve with a squared correlation coefficient $\left(R^{2}\right) \geq 0.995$. Analytical uncertainties were propagated from the standard deviation of the field blank value and $10 \%$ of the measured concentration. For analytes not detected in the field blank, instrument detection limits were used in error propagation. All measurements were fieldblank-subtracted. Due to low recoveries of furandiones from PUF, gas-phase concentrations of furandiones were corrected for the recoveries of the authentic standards.

\subsection{Particle-phase fraction calculation and model}

The fraction of a species in the particle phase $\left(F_{\mathrm{p}}\right)$ was calculated from the ratio of concentration in the particle phase to the total concentration (sum of gas and particle), following Eq. (1).

$F_{\mathrm{p}}=\frac{[\text { particle }]}{[\text { gas }]+[\text { particle }]}$ 
$F_{\mathrm{p}}$ was modelled using the gas-particle partitioning coefficient (Eq. 2) from absorptive partitioning theory developed by Pankow (1994), and following Yatavelli et al. (2014):

$$
F_{\mathrm{p}}=\left(1+\frac{1}{k_{\mathrm{om}} \times C_{\mathrm{OA}}}\right)^{-1}
$$

where $C_{\mathrm{OA}}$ is the concentration of the organic aerosol $\left(\mu \mathrm{g} \mathrm{m}^{-3}\right)$ and $k_{\mathrm{om}}$ is the partitioning coefficient $\left(\mathrm{m}^{3} \mu \mathrm{g}^{-1}\right)$ described as

$k_{\mathrm{om}}=\frac{R T}{10^{6} P_{L}^{0} \mathcal{E} \mathrm{MW}}$,

in which $R$ is an ideal gas constant $\left(8.2 \times 10^{-5} \mathrm{~m}^{3}\right.$ atm mol $\left.{ }^{-1} \mathrm{~K}^{-1}\right) ; \quad T$ is temperature (averaging $9{ }^{\circ} \mathrm{C}$ during this study); $10^{6}$ is a unit conversion factor $\left(\mu \mathrm{g} \mathrm{g}^{-1}\right) ; P_{\mathrm{L}}^{0}$ is the sub-cooled vapour pressure (atm), obtained from the Estimation Program Interface suite ${ }^{\mathrm{TM}}$ version 4.11 from the Environmental Protection Agency (EPA); $\mathrm{MW}$ is the molar mass $\left(\mathrm{g} \mathrm{mol}^{-1}\right)$; and $\mathcal{E}$ is the activity coefficient (set equal to $0.3,1$, and 3 ).

\subsection{Statistical analysis}

Inter-species correlations were evaluated using Minitab software (version 16). The Anderson-Darling test for normality indicated that neither ambient concentrations nor log-transformed concentrations were normally distributed. Hence, Spearman's rho $\left(r_{\mathrm{s}}\right)$ was used to assess correlations. Correlations were interpreted as follows: very high (0.9-1.0), high (0.7-0.9), moderate (0.5-0.7), low (0.3-0.5), and negligible (0.0-0.3) (Mukaka, 2012). The statistical significance of correlations was evaluated at the $95 \%$ confidence interval $(p \leq 0.05)$.

\section{Results and discussion}

\subsection{Validation of gas-particle partitioning}

PAHs with two to five rings span a range of high to low volatility, respectively. The accuracy of the measured gasparticle distributions were evaluated with $\mathrm{PAHs}$ that have been extensively discussed in the literature. The average fractions of PAH in the particle phase $\left(F_{\mathrm{p}}\right)$ measured in Iowa City, IA, USA (Fig. 1), were $\sim 5 \%$ for $10-14$ carbon atoms (two-three rings: naphthalene, acenaphthene, and anthracene), $14 \%$ for 16 carbon atoms (four rings: pyrene), $59 \%$ for 18 carbons (four rings: benzo(ghi)fluoranthene), and $>98 \%$ for 20 carbon atoms (five rings: picene). The predicted $F_{\mathrm{p}}$ values estimated using the Pankow absorption model (1994) following Eqs. (1) and (2) and using parameters in Table S1 in the Supplement follow the same trend (Fig. 1, dashed line), with a systematic underestimation for the predicted $F_{\mathrm{p}}$ by $\leq 12 \%$ for most PAHs and $20 \%$ for

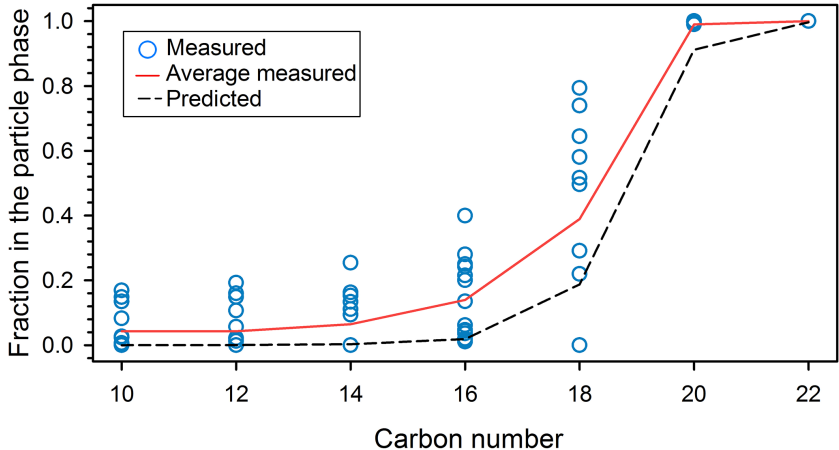

Figure 1. Fraction of PAHs in the particle phase as a function of the number of carbon atoms. Circles represent the daily measured $F_{\mathrm{p}}(n=14)$, the red line represents average $F_{\mathrm{p}}$, and the dotted line (black) is the predicted $F_{\mathrm{p}}$ using the absorption model (Table S1). Select PAHs were used compare ambient measurements and model estimation: $\mathrm{C}_{10}$ is naphthalene, $\mathrm{C}_{12}$ is acenaphthene, $\mathrm{C}_{14}$ is anthracene, $\mathrm{C}_{16}$ is pyrene, $\mathrm{C}_{18}$ is benzo(ghi)fluoranthene, $\mathrm{C}_{20}$ is benzo(b)fluoranthene, and $\mathrm{C}_{22}$ is picene.

18 carbons. Such an underestimation has been widely documented in comparison of theory to ambient partitioning studies and is attributed to the omission of PAH sorption on elemental carbon in the model (Dachs and Eisenreich, 2000; He and Balasubramanian, 2009; Wang et al., 2011). Ambient studies of gas-particle partitioning are influenced by many factors such as ambient temperatures (Terzi and Samara, 2004), relative humidity (Pankow et al., 1993), and sampling technique (reviewed by Kim and Kim, 2015), confounding direct comparisons between this and other studies. Overall, the general trends observed herein are consistent with prior studies that report PAHs with two-three aromatic rings $\left(\mathrm{C}_{10}\right.$ $\left.\mathrm{C}_{14}\right)$ mainly in the gas phase $\left(F_{\mathrm{p}} \geq 0.93\right)$, those with five or more aromatic rings $\left(\geq \mathrm{C}_{20}\right.$ ) mainly in the particle phase $\left(F_{\mathrm{p}} \geq 0.9\right)$, and those with four aromatic rings $\left(\mathrm{C}_{16}\right.$ and $\left.\mathrm{C}_{18}\right)$ partitioned between the two phases depending on their chemical structure and atmospheric conditions (Yamasaki et al., 1982; Williams et al., 2010; Ma et al., 2011; Kim and Kim, 2015).

Gas-phase sampling using QFF without a denuder upfront is subject to artefacts caused by vapour adsorption on the filter, resulting in underestimation of the concentration of the species in the gas phase, particularly for low-MW PAHs (Delgado-Saborit et al., 2014). However, comparing the partitioning trend in this study to those sampled with a denuder during the same season (Possanzini et al., 2004) shows less than $5 \%$ discrepancies for the low $(\mathrm{C} \leq 12)$ and high $(\mathrm{C} \geq 18)$ molecular weight PAHs, while for $\mathrm{C}_{14}$ and $\mathrm{C}_{16}$ our $F_{\mathrm{p}}$ measurements were lower by 14 and $6 \%$, respectively. These results show a slight underestimation of $F_{\mathrm{p}}$ rather than an overestimation, which would be expected if vapour adsorption on the QFF significantly impacted gas-particle partitioning results. We estimate that the uncertainties associated 


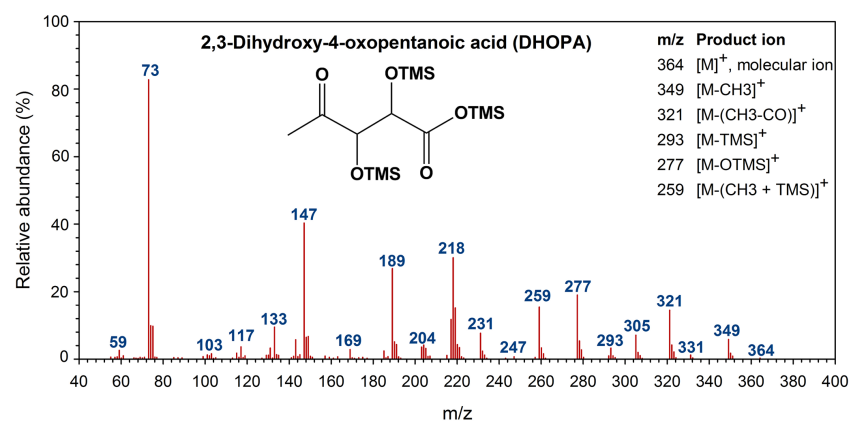

Figure 2. Mass spectrum of the trimethylsilylateted derivatives of 2,3-dihydroxy-4-oxopentanoic acid by electron impact ionization.

with our gas-particle partitioning measurements are $\leq 5 \%$ for species predominantly in the particle phase $\left(F_{\mathrm{p}}>0.9\right)$ or gas phase $\left(F_{\mathrm{p}}<0.1\right)$ and are in the range of $14 \%$ for semivolatile species $\left(0.1<F_{\mathrm{p}}<0.9\right)$.

\subsection{The toluene tracer (2,3-dihydroxy-4-oxopentanoic acid)}

\subsubsection{GC-MS identification}

2,3-Dihydroxy-4-oxopentanoic acid (DHOPA, also known as T-3) has been identified as a product of toluene photooxidation by Kleindienst et al. (2004), and their chemical ionization mass spectrum has been used to identify this tracer in other studies. To support identification by the more common EI, the corresponding mass spectrum of its trimethylsilylated (TMS) derivative is given in Fig. 2. The most abundant ions are $m / z 73$ and 147 , corresponding to $\mathrm{Si}\left(\mathrm{CH}_{3}\right)_{3}{ }^{+}$and $\left(\mathrm{CH}_{3}\right)_{2} \mathrm{Si}=\mathrm{O} \mathrm{Si}\left(\mathrm{CH}_{3}\right)_{3}{ }^{+}$fragments, respectively; however, these are common to the BSTFA-TMCS silylation reagent. Ions at $m / z 277,349,321$, and 364 are unique to DHOPA and are recommended for quantification. Here, the $m / z 277$ ion was used for quantification due to the high relative abundance and low background, and the other ions were used qualitatively. This mass spectrum obtained from a pure standard builds upon the previous EI mass spectrum for the DHOPA in an aerosol sample by Hu et al. (2008) that included some spectral interferences from adipic acid that coeluted.

\subsubsection{Ambient concentration and gas-particle partitioning}

The average mass concentration of DHOPA ranged from 0.14 to $0.50 \mathrm{ng} \mathrm{m}^{-3}$ and averaged $0.29 \pm 0.12 \mathrm{ng} \mathrm{m}^{-3}$ (Fig. 3a). DHOPA was detected only in the particle phase (Table 2), although the $22.1 \pm 13.5 \%$ extraction recoveries of this species from PUF limited the sensitivity of gas-phase measurements. Nonetheless, it is reasonable to conclude that this species does not appreciably partition to the gas phase.

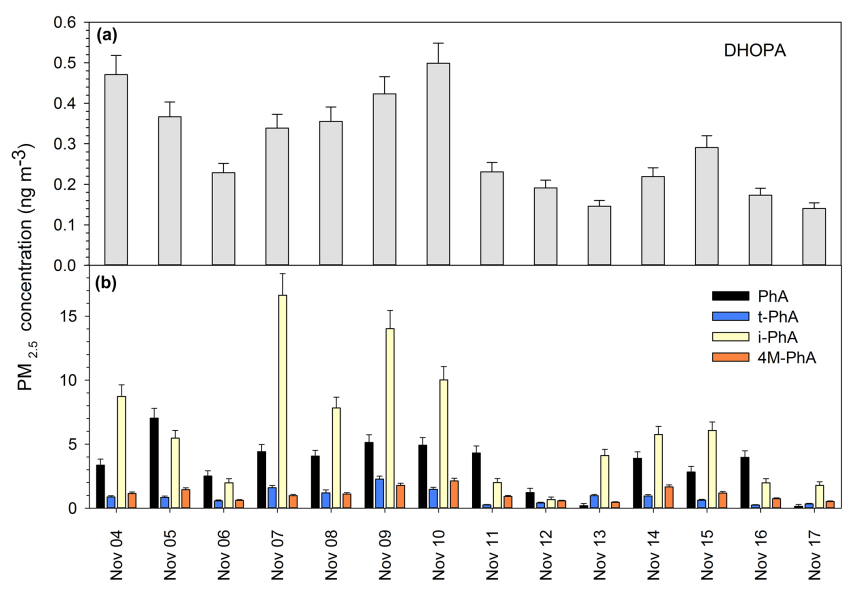

Figure 3. Daily $\mathrm{PM}_{2.5}$ concentrations for 2,3-dihydroxy-4oxopentanoic acid (a) and benzene dicarboxylic acids (b), where $\mathrm{PhA}$ is phthalic acid, t-PhA is terephthalic acid, $\mathrm{i}-\mathrm{PhA}$ is isophthalic acid, and 4M-PhA is 4-methylphthalic acid.

The average concentrations of DHOPA in Iowa City were within the range of those observed in Bondville, IL, in autumn (Lewandowski et al., 2008) but were lower by a factor of 45 (on average) than what was detected in the Pearl River Delta, China, for the same season (Ding et al., 2012). Although an authentic standard for DHOPA was not previously available, prior measurements were based upon a surrogate standard response and are subject to bias.

The contribution of toluene SOA to OC was estimated based on the SOA tracer method introduced by Kleindienst et al. (2007), where the DHOPA mass fraction of SOC from toluene was $0.0079 \pm 0.0026$. Following this estimation method, toluene SOC was estimated to contribute $36.5 \pm 15.0 \mathrm{ngC} \mathrm{m}^{-3}$. The contribution of the estimated SOC to the total OC in this study ranged $0.3-7 \%$ and averaged $2.2 \pm 1.6 \%$. In other studies, the concentration of toluene SOC was variable and influenced by seasonal variations and local emission sources (Kleindienst et al., 2007; Peng et al., 2013). Our estimated SOC levels were less than half of those observed in the rural Midwestern United States previously $\left(0.09 \mu \mathrm{g} \mathrm{m}^{-3}\right)$ during the same season; however the contribution of the estimated toluene SOC to the total OC was $6 \%$ (Lewandowski et al., 2008), which is within the upper end of the range observed in this study. Although toluene SOC concentrations were much higher in the Pearl River Delta $\left(1.65 \mu \mathrm{g} \mathrm{m}^{-3}\right)$ (Ding et al., 2012), its relative contribution to OC $(7 \%)$ was comparable. Because toluene is only one of many aromatic VOC precursors to SOA, additional tracers are needed to better evaluate the impact of aromatic VOCs on SOA.

\subsection{Benzene dicarboxylic acids}

Three isomers of benzene dicarboxylic acid and one methyl derivative were detected in all PM samples. The total (gas 
Table 1. Method performance parameters for nitromonoaromatics, including GC retention time $\left(t_{\mathrm{R}}\right)$, instrument detection limit (IDL), instrument quantitation limit (IQL), and mean extraction recoveries ( \pm 1 standard deviation for $n=3)$.

\begin{tabular}{|c|c|c|c|c|c|c|c|c|}
\hline \multirow[t]{2}{*}{ Nitromonoaromatic } & \multirow{2}{*}{$\begin{array}{c}t_{\mathrm{R}} \\
(\min )\end{array}$} & \multirow{2}{*}{$\begin{array}{c}\text { Base peak* } \\
(m / z)\end{array}$} & \multirow{2}{*}{$\begin{array}{l}\text { Linear range } \\
\qquad\left(\mu \mathrm{g} \mathrm{L}^{-1}\right)\end{array}$} & \multirow{2}{*}{$\begin{array}{l}\text { Linear regression } \\
\qquad R^{2}\end{array}$} & \multirow{2}{*}{$\begin{array}{c}\mathrm{IDL} \\
\left(\mu \mathrm{g} \mathrm{L}^{-1}\right)\end{array}$} & \multirow{2}{*}{$\begin{array}{c}\mathrm{IQL} \\
\left(\mu \mathrm{g} \mathrm{L}^{-1}\right)\end{array}$} & \multicolumn{2}{|c|}{ Extraction recovery } \\
\hline & & & & & & & $\begin{array}{c}\text { Filter } \\
(\%)\end{array}$ & $\begin{array}{c}\text { PUF } \\
(\%)\end{array}$ \\
\hline 4-Nitrophenol-D4 (IS) (4NP-D4) & 9.66 & 200 & - & - & - & - & - & - \\
\hline 4-Nitrophenol (4NP) & 9.69 & 196 & $50-5000$ & 0.999 & 13.2 & 43.9 & $100.5 \pm 2.2$ & $97.9 \pm 2.2$ \\
\hline 4-Methyl-2-nitrophenol (4M-2NP) & 9.71 & 210 & $10-5000$ & 0.999 & 2.7 & 8.8 & $96.7 \pm 2.8$ & $100.3 \pm 0.6$ \\
\hline 4-Methyl-3-nitrophenol (4M-3NP) & 9.71 & 208 & $40-5000$ & 0.999 & 11.4 & 38.0 & $100.2 \pm 0.5$ & $97.1 \pm 3.2$ \\
\hline 2-Methyl-4-nitrophenol (2M-4-NP) & 11.08 & 210 & $50-5000$ & 0.999 & 14.5 & 48.2 & $99.7 \pm 0.8$ & $99.0 \pm 1.6$ \\
\hline 4-Nitroguaiacol (4NG) & 12.08 & 211 & $50-5000$ & 0.999 & 14.9 & 49.5 & $94.2 \pm 2.4$ & $97.9 \pm 2.2$ \\
\hline 5-Nitroguaiacol (5NG) & 12.40 & 211 & $30-5000$ & 0.998 & 6.7 & 22.4 & $96.2 \pm 3.3$ & $97.4 \pm 1.7$ \\
\hline 4-Nitrocatechol (4NC) & 13.13 & 284 & $40-5000$ & 0.999 & 10.1 & 33.8 & $102.5 \pm 2.9$ & $49.9 \pm 17.0$ \\
\hline 4-Methyl-5-nitrocatechol (4M-5NC) & 13.66 & 313 & $40-5000$ & 0.999 & 9.1 & 30.3 & $108.1 \pm 1.8$ & $41.5 \pm 24.8$ \\
\hline 4-Hydroxy-3-nitrobenzyl alcohol (4H-3NB) & 14.23 & 298 & $20-5000$ & 0.998 & 6.3 & 21.0 & $95.6 \pm 2.5$ & $103.3 \pm 3.5$ \\
\hline 3-Nitrosalicylic acid-D3 (IS) (3NSA-D3) & 14.08 & 315 & - & - & - & - & - & - \\
\hline 5-Nitrosalicylic acid (5NSA) & 15.11 & 312 & $20-5000$ & 0.996 & 5.1 & 16.9 & $100.2 \pm 1.0$ & $95.0 \pm 3.1$ \\
\hline
\end{tabular}

$* m / z$ are given for trimethylsilylated derivatives of all analytes.

plus particle) concentration of phthalic acid ( $\mathrm{PhA})$, the most abundant isomer, ranged from 4.9 to $21.5 \mathrm{ng} \mathrm{m}^{-3}$ and averaged $13.0 \pm 4.3 \mathrm{ng} \mathrm{m}^{-3}$, while isophthalic acid (i-PhA), terephthalic acid (t-PhA) and 4-methylphthalic acid (4M$\mathrm{PhA}$ ) had increasingly lower concentrations in the range of 0.2 to $6.6 \mathrm{ng} \mathrm{m}^{-3}$ (Fig. 3b). Similar relative abundancies for these species were observed in other studies, with $\mathrm{PhA}$ consistently being the predominant isomer (Fraser et al., 2003; Mirivel et al., 2011; Mkoma and Kawamura, 2013). The relatively high ambient mass concentrations of these dicarboxylic acid isomers at levels that allow for consistent detection make them promising candidates for tracing aromatic SOA.

The majority of PhA was estimated to be in the gas phase $\left(F_{\mathrm{p}}=0.26\right)$, in contrast to i-PhA and $\mathrm{t}-\mathrm{PhA}\left(F_{\mathrm{p}}=1\right)$ and $4-\mathrm{M}-\mathrm{PhA}\left(F_{\mathrm{p}}=0.82\right.$, Table 2$)$. Vapour pressure values and partitioning theory (Table S1 in the Supplement) cannot explain the observed lower fraction of $\mathrm{PhA}$ in the particle phase compared to i-PhA and $\mathrm{t}-\mathrm{PhA}\left(F_{\mathrm{p}}=1\right)$. Instead, the gasphase measurement of $\mathrm{PhA}$ is expected to be positively biased due to interference by phthalic anhydride, which yields identical products to $\mathrm{PhA}$ when derivatized, hydrolysed, or exposed to high temperatures (like those encountered in GC analysis). For example, under the conditions employed in this study, phthalic anhydride and PhA have identical GC retention time and silylated MS spectra (Fig. S1 in the Supplement). Phthalic anhydride is a gas-phase product of naphthalene photooxidation (Chan et al., 2009; Kautzman et al., $2010)$ and has much higher vapour pressure $\left(7.5 \times 10^{-6} \mathrm{~atm}\right)$ than that of PhA $\left(8.9 \times 10^{-8} \mathrm{~atm}\right)(\mathrm{EPA}, 2012)$. As such, phthalic anhydride will partition to a greater extent to the gas phase, which is supported by the absorption model estimations $\left(F_{\mathrm{p}}=4.9 \times 10^{-5}\right)$, shown in Table S1. Thus, PhA concentrations reported here and in prior studies that involve the use of GC inlet temperatures $\geq 150^{\circ} \mathrm{C}$, derivatization, or hydrolysis (which is common in liquid chromatography) reflect the sum of PhA and phthalic anhydride. Because phthalic anhydride is primarily in the gas phase, this causes gas-phase $\mathrm{PhA}$ concentrations to be overestimated and $F_{\mathrm{p}}$ estimates for $\mathrm{PhA}$ to be erroneously low. An accurate determination of $F_{\mathrm{p}}$ for $\mathrm{PhA}$ requires collection and analysis of acid and anhydrides separately by in situ derivatization on veratrylaminecoated glass fibre filters (OSHA, 1991).

Although $\mathrm{PhA}$ and 4M-PhA can be emitted directly from primary sources such as motor vehicle engines (Kawamura and Kaplan, 1987), there is a lack of evidence for significant primary source contributions to these species in ambient air. In contrast, naphthalene, a precursor for secondary formation of PhA (Kautzman et al., 2010; Kleindienst et al., 2012), was found to be the most abundant PAH from many combustion sources (Oanh et al., 1999; Al-Naiema et al., 2015). As shown in Table S3, the concentrations of PhA and 4M-PhA in the particle phase are highly and significantly correlated with DHOPA $\left(r_{\mathrm{s}}=0.73, p=0.003 ; r_{\mathrm{s}}=0.79, p=0.001\right.$, respectively), but they do not correlate with hopane $\left(r_{\mathrm{s}}=0.19\right.$, $p=0.529$ ), a fossil fuel combustion biomarker. These correlation data indicate that the probable origin of these two acids is secondary reactions, rather than primary emissions. Although i-PhA has a strong correlation with DHOPA, it also correlates highly and significantly with biomass burning products (e.g. levoglucosan, 4-nitrocatechol, and 4-methyl5-nitrocatechol) and moderately with hopane. The possibility of multiple sources of i-PhA limits its application as a tracer for anthropogenic SOA. Terephthalic acid correlates strongly with biomass burning tracers and with hopane, and there is no evidence supporting secondary formation; hence, $\mathrm{t}-\mathrm{PhA}$ is not a valid SOA tracer candidate. The relatively high concentrations of $\mathrm{PhA}$ and $4 \mathrm{M}-\mathrm{PhA}$ detected in the particle phase and their strong correlations with DHOPA suggest that these compounds are useful SOA tracers for naphthalene and methylnaphthalene photooxidation, respectively. 


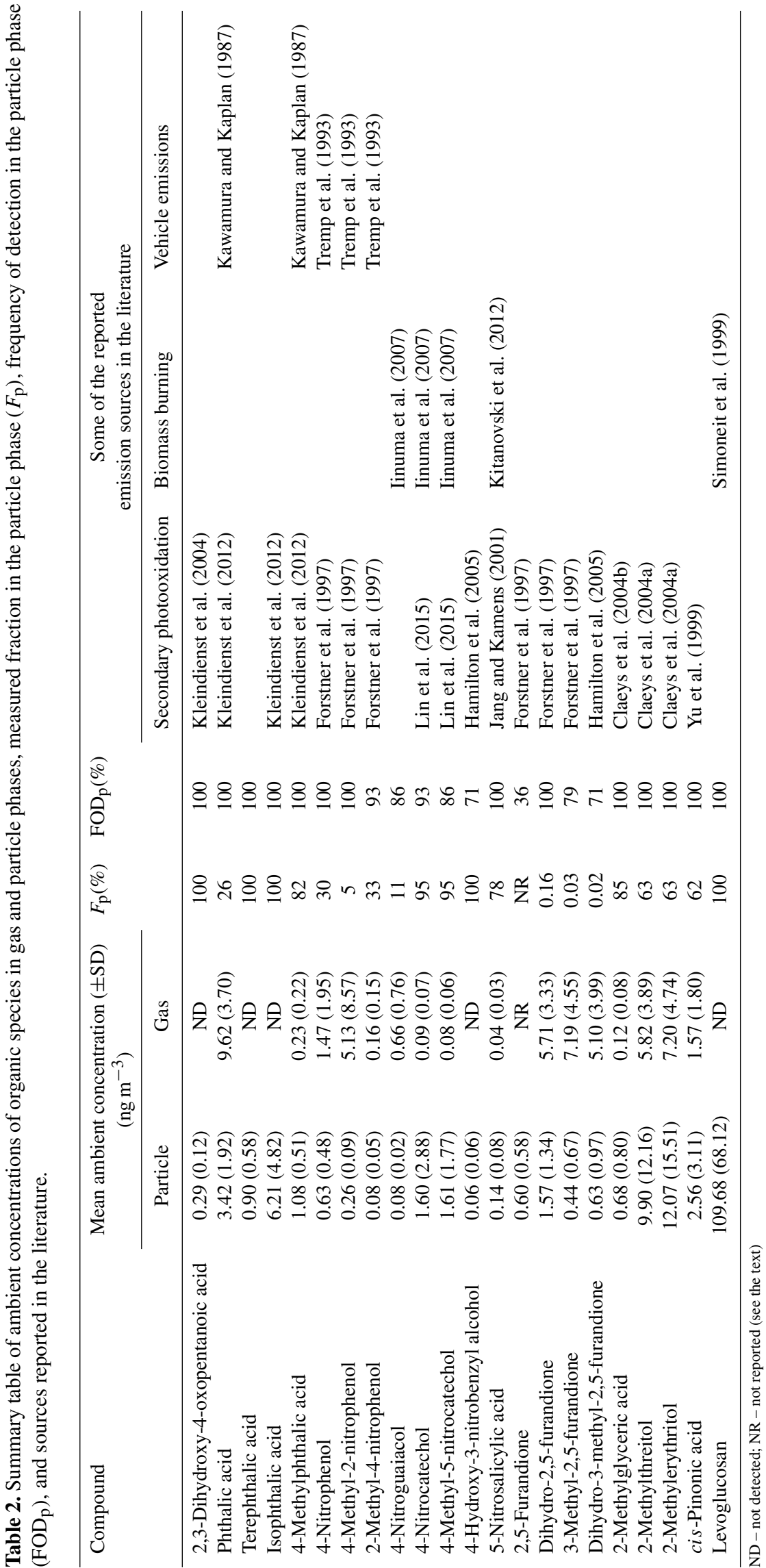




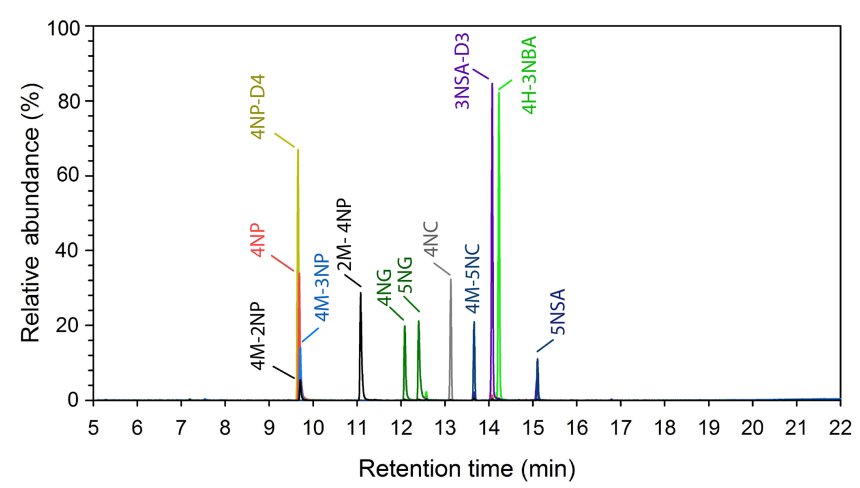

Figure 4. Selected ion chromatogram for a mixture of nitromonoaromatics standard $\left(5 \mathrm{ng} \mathrm{mL}^{-1}\right)$, where $4 \mathrm{M}-2 \mathrm{NP}$ is 4 methyl-2-nitrophenol, $4 \mathrm{NP}$ is 4-nitrophenol, $4 \mathrm{NP}-\mathrm{D}_{4}$ is 4nitrophenol- $\mathrm{D}_{4}, 4 \mathrm{M}-3 \mathrm{NP}$ is 4-methyl-3-nitrophenol, 2M-4-NP is 2-methyl-4-nitrophenol, $4 \mathrm{NG}$ is 4-nitroguaiacol, 5-NG is 5nitroguaiacol, 4NC is 4-nitrocatechol, $4 \mathrm{M}-5 \mathrm{NC}$ is 4-methyl-5nitrocatechol, $3 \mathrm{NSA}_{-} \mathrm{D}_{3}$ is 3-nitrosalicylic acid-D 3 , 4H-3NB is 4hydroxy-3-nitrobenzyl alcohol, and 5NSA is 5-nitrosalicylic acid.

\subsection{Nitromonoaromatic compounds}

\subsubsection{Analytical method performance}

While many techniques for quantifying nitrophenols in various sample matrices have been developed and were reviewed by Harrison et al. (2005), our goal was to quantify these compounds in parallel to other primary and secondary source tracers using GC-MS and single-filter extraction protocol. Using GC with a DB-5 column, a baseline separation was achieved for 10 nitromonoaromatic analytes as trimethylsilylated esters (Fig. 4), with highly symmetrical and narrow peak shapes. Mass spectrometry was used for identification by comparison of retention times and mass spectra, and quantification was done based on base peak area (Table S2). Nitromonoaromatic mass spectra (Table S2) included mass fragments with $m / z[\mathrm{M}-60]^{+}$(from the loss of $\mathrm{NO}_{2}$ and $\mathrm{CH}_{3}$ ), where $\mathrm{M}$ is molecular ion for the trimethylsilylated ester. Save for nitroguiacols and 4-methyl-5-nitrocatechol, nitromonoaromatics' mass spectra included a mass fragment of $[\mathrm{M}-15]^{+}$(loss of $\mathrm{CH}_{3}$ ). The mass spectra for the coeluting peaks (Fig. 4) indicate that potential interferences for the $4 \mathrm{NP}-\mathrm{D}_{4}, 4 \mathrm{NP}$, and $4 \mathrm{M}-2 \mathrm{NP}$ are not appreciably strong $(<1 \%)$, and thus interferences are expected to be negligible. There is potential for $4 \mathrm{M}-3 \mathrm{NP}$ to interfere with detection of $4 \mathrm{M}-2 \mathrm{NP}$, because the former shows a relatively strong signal for $m / z 210$ (at $38 \%$ of the base peak signal) that is used to quantify the latter; however 4M-3NP was not detected in this study, so no interference is expected in this dataset.

The performance of the GC-MS method was evaluated with respect to linearity, detection and quantification limits of target analytes, and extraction efficiency (Table 1). The normalized response for the nitromonoaromatics was linear

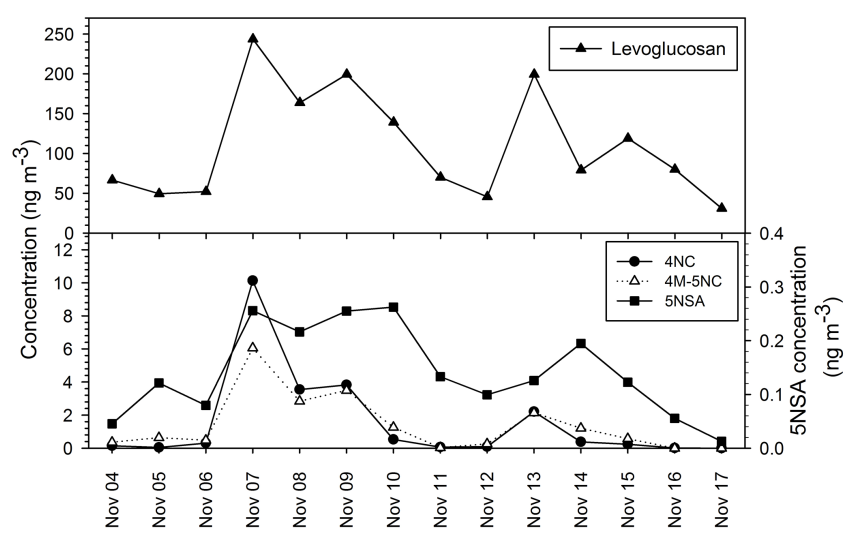

Figure 5. Time series of ambient $\mathrm{PM}_{2.5}$ concentration of levoglucosan, 4-nitrocatechol (4-NC), 4-methyl-5-nitrocatechol (4-M5NC), and 5-nitrosalicylic acid (5NSA).

( $R^{2} \geq 0.996$ ) from 10 to $5000 \mu \mathrm{g} \mathrm{L}-1$ with a constant internal standard concentration of $10000 \mu \mathrm{g} \mathrm{L}^{-1}$. This wide range of linearity indicates the suitability of this method to determine nitromonoaromatics in different applications. The limit of detection ranges from 2.7 to $14.9 \mu \mathrm{g} \mathrm{L}^{-1}$ for the $10 \mathrm{ni}-$ tromonoaromatic compounds. These method detection limits are higher than those obtained from liquid chromatography coupled with tandem mass spectrometry $\left(0.1-0.25 \mu \mathrm{g} \mathrm{L}^{-1}\right)$ (Kitanovski et al., 2012) but are sufficient to detect the investigated species in ambient air. Filter extraction recoveries averaged $99.4 \pm 3.8 \%$, demonstrating high accuracy and precision of the filter extraction with acetonitrile and reduction in volume under reduced pressure with rotary evaporation. For PUF extraction, very high recovery (>97\%) was achieved for most compounds (Table 1); however two nitrocatechols, $4 \mathrm{NC}$ and $4 \mathrm{M}-5 \mathrm{NC}$, had significantly lower $(<50 \%)$ and much more variable (relative standard deviation (RSD): 34 $60 \%$ ) recoveries. Similarly low recoveries of $4 \mathrm{NC}$ and $4 \mathrm{M}-$ $5 \mathrm{NC}$ have been reported previously (Hawthorne et al., 1989), which is attributed to the strong interactions of phenols with the polymeric chains of the PUF. Consequently, gas-phase measurements of $4 \mathrm{NC}$ and $4 \mathrm{M}-5 \mathrm{NC}$ are biased low and subject to high uncertainty, such that their levels and gas-particle partitioning are not reported. Otherwise, the extraction and analysis method provides high accuracy and reliable precision for nitromonoaromatics from filters and PUF.

\subsubsection{Ambient concentration, gas-particle partitioning, and potential sources}

Total concentrations of eight nitromonoaromatics ranged from 0.7 to $17 \mathrm{ng} \mathrm{m}^{-3}$ in the particle phase and from 0.6 to $40 \mathrm{ng} \mathrm{m}^{-3}$ in the gas phase (Figs. 5 and S3). Average concentrations and $F_{\mathrm{p}}$ are summarized in Table 2, with daily $F_{\mathrm{p}}$ shown in Fig. S2.

A number of nitromonoaromatics were likely derived from biomass burning, as evidenced by correlations with 
a biomass burning marker (levoglucosan) in this and prior studies. Nitrocatechols were the most abundant particlephase species within this compound class, with average concentrations ( \pm standard deviation) of $1.6 \pm 2.9 \mathrm{ng} \mathrm{m}^{-3}$ and $1.6 \pm 1.8 \mathrm{ng} \mathrm{m}^{-3}$ for $4 \mathrm{NC}$ and $4 \mathrm{M}-5 \mathrm{NC}$, respectively. These two species have been previously associated with biomass burning in $\mathrm{PM}_{10}$, via their correlations with levoglucosan (Iinuma et al., 2010; Kahnt et al., 2013). The strong correlation of these two species with levoglucosan extends to $\mathrm{PM}_{2.5}$ in Iowa City (Fig. 5) with very high correlations with levoglucosan for $4 \mathrm{NC}\left(r_{\mathrm{s}}=0.90, p<0.001\right)$ and $4 \mathrm{M}$ $5 \mathrm{NC}\left(r_{\mathrm{s}}=0.85, p<0.001\right)$. Although nitrocatechol can be formed from the toluene photooxidation (Lin et al., 2015), $4 \mathrm{NC}$ correlates weakly with DHOPA $\left(r_{\mathrm{s}} \leq 0.2\right)$ lacking statistical significance (Table S3), suggesting that toluene photooxidation is negligible in relation to biomass burning. Similarly, 5NSA $\left(F_{\mathrm{p}}=0.73\right)$ was highly correlated with levoglu$\operatorname{cosan}\left(r_{\mathrm{s}}=0.76, p=0.002\right)$ but moderately correlated with DHOPA $\left(r_{\mathrm{s}}=0.49, p=0.078\right)$, also suggesting its primary origin to be biomass burning (Kitanovski et al., 2012; Zhang et al., 2013) rather than photooxidation (Jang and Kamens, 2001), in agreement with prior studies. Consequently, these three species are characteristic of biomass burning, rather than anthropogenic SOA.

Nitroguaiacol was detected in low concentrations relative to other nitromonoaromatics. The concentrations of $4 \mathrm{NG}$ in $\mathrm{PM}_{2.5}$ ranged from below the detection limit (BDL) to $0.11 \mathrm{ng} \mathrm{m}^{-3}$, with a frequency of detection of $86 \%$ (Table 2). Similarly low concentrations were also reported elsewhere (Kitanovski et al., 2012). In the gas phase, 4NG was not detected on most of the days, except for 14-16 November, when gas concentrations reached $0.5-2.1 \mathrm{ng} \mathrm{m}^{-3}$ (Fig. S2). On 14 November, outdoor festivities, barbecues, and slowmoving traffic occurred near the sampling site. The possibility of multiple sources and the low ambient concentrations suggest that this is not a suitable tracer for anthropogenic SOA.

$4 \mathrm{H}-3 \mathrm{NB}$ was detected only in the particle phase $\left(F_{\mathrm{p}}=1\right)$, with a frequency of $71 \%$ and relatively low concentrations ranging from $\mathrm{BDL}$ to $0.2 \mathrm{ng} \mathrm{m}^{-3}$. $4 \mathrm{H}-3 \mathrm{NB}$ was identified as a low-abundance product of toluene photooxidation with hydroxyl radicals (Hamilton et al., 2005; Fang et al., 2011). Other than toluene photooxidation, there are no other known emission sources for $4 \mathrm{H}-3 \mathrm{NB}$. The specificity of $4 \mathrm{H}-3 \mathrm{NB}$ is supported by the lack of correlation with other biogenic or anthropogenic tracers (Table S3). Because it is detected only in the particle phase and is likely specific to toluene photooxidation, it has potential to be a unique nitromonoaromatic tracer for anthropogenic VOC photooxidation. However, due to the small number of samples and the frequency of detection for this tracer, further investigation is recommended to evaluate its detectability in other environments and source specificity.

In addition, 4NP was consistently detected, with summed gas and particle concentration of $4 \mathrm{NP}$ ranging from 0.3

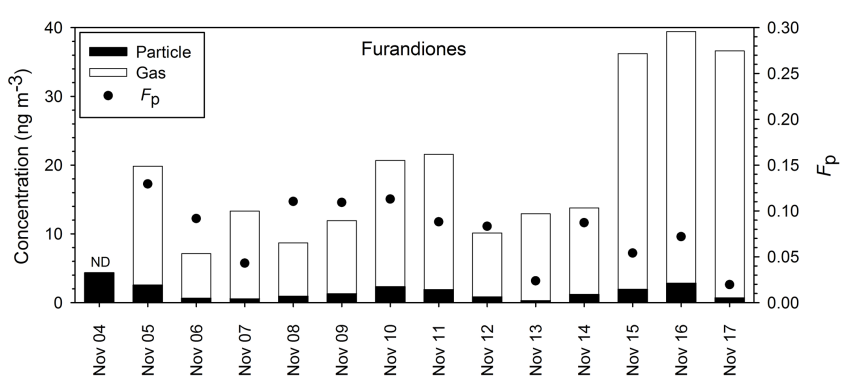

Figure 6. Time series of the measured furandiones $(2,5-$ furandione (FD), dihydro-2,5-furandione (DFD), 3-methyl-2,5furandione (MFD), and dihydro-3-methyl-2,5-furandione (DMFD)) detected in gas and particle phases, with the measured fraction in the particle phase $\left(F_{\mathrm{p}}\right)$. Furandiones were not detected in the gas phase on 4 November 2015. Due to poor extraction recoveries, the gas-phase concentration of FD was not reported.

to $7.3 \mathrm{ng} \mathrm{m}^{-3}$ and averaging $1.8 \pm 2.1 \mathrm{ng} \mathrm{m}^{-3}$. Likewise, two methyl-nitrophenol isomers (4M-2NP and $2 \mathrm{M}-4 \mathrm{NP})$ averaged $0.3 \pm 1.6 \mathrm{ng} \mathrm{m}^{-3}$ and $5.3 \pm 8.5 \mathrm{ng} \mathrm{m}^{-3}$, respectively (Table 2 and Fig. S3). The higher concentration of 4M$2 \mathrm{NP}$ with the higher standard deviation is largely driven by the aforementioned local source influences on 14 November $\left(32.5 \mathrm{ng} \mathrm{m}^{-3}\right)$, shown in Fig. S2. These three nitromonoaromatics showed substantial partitioning in the gas phase, with $F_{\mathrm{p}} \leq 0.33$ (Table 2). The very high correlation of $4 \mathrm{NP}$ with $2 \mathrm{M}-4 \mathrm{NP}\left(r_{\mathrm{s}}=0.90, p<0.001\right)$ and with $4 \mathrm{M}-2 \mathrm{NP}\left(r_{\mathrm{s}}=\right.$ $0.81, p<0.001)$ indicates a similar source of origin. These three compounds have previously been shown to be products from the photooxidation of the monoaromatic compounds in the presence of $\mathrm{NO}_{x}$ (Forstner et al., 1997; Harrison et al., 2005; Sato et al., 2007) as well as components of vehicle emissions (Tremp et al., 1993). However, no significant correlations were observed between these tracers with hopane or DHOPA. Because of their lack of source specificity and the significant partitioning in the gas phase, these three nitrophenols are not recommended for use as tracers of anthropogenic SOA.

\subsection{Furandiones}

Ambient gas and particle concentrations for the sum of four furandiones and their $F_{\mathrm{p}}$ are shown in Fig. 6, with individual species data in Fig. S4. The total furandiones concentration detected in the particle phase ranged from 0.3 to $4.3 \mathrm{ng} \mathrm{m}^{-3}$ and averaged $1.6 \pm 1.1 \mathrm{ng} \mathrm{m}^{-3}$. These concentrations were lower than those detected in our previous study $\left(9.3 \pm 3.0 \mathrm{ng} \mathrm{m}^{-3}\right.$ ) (Al-Naiema et al., 2017), which is likely due to the rainy and foggy weather in the autumn of 2015. In the presence of water, anhydrides undergo hydration and ring opening to form the carboxylic acid derivatives. The relative rate of hydrolysis for 2,5-furandione (FD) and 3-methyl-2,5-furandione (MFD) are 6 times higher than dihydro-2,5-furandione (DFD) and dihydro-3-methyl-2,5,- 
furandione (DMFD) (Trivedi and Culbertson, 1982). The highest stability against water hydrolysis might explain the higher concentration of DFD detected in this study compared to other furandiones. The sum of the gas-phase concentration for the furandiones (DFD, MFD, and DMFD) averaged $18.0 \pm 10.7 \mathrm{ng} \mathrm{m}^{-3}$.

Furandiones were almost entirely in the gas phase (Fig. S4). The measured $F_{\mathrm{p}}$ values were 0.31 for DFD, 0.08 for MFD, and 0.05 for DMFD, while this value is not reported for FD, which showed poor extraction recovery $(<10 \%)$ from the PUF. Low $F_{\mathrm{p}}$ values are expected for furandiones due to their high vapour pressures (Table $\mathrm{S} 1$ ). The measured $F_{\mathrm{p}}$ values were substantially higher than those predicted by Pankow's absorption model by 2 orders of magnitude (Tables 2 and S1). It is possible that higher-thanpredicted $F_{\mathrm{p}}$ values were driven by furandione adsorption on the front filter or breakthrough from the PUF (Chuang et al., 1987).

Although no sources other than photooxidation of anthropogenic VOCs are known to influence the atmospheric concentration of furandiones (Forstner et al., 1997; Hamilton et al., 2005), only a moderate correlation $\left(r_{\mathrm{s}}=0.50, p=0.064\right)$ was observed between the particle concentrations of furandiones with DHOPA (Table S3). This may be due to the fact that DHOPA is a tracer specific to toluene, while furandiones can also form from other aromatic VOCs (Forstner et al., 1997). Overall, we conclude that furandiones hold a significant importance to serve as indicators for atmospherically processed aromatic VOCs due to their source specificity; however the substantial partitioning toward the gas phase and their water sensitivity limit their application as SOA tracers.

\section{Conclusions}

This study evaluates, for the first time, the influence of the source specificity, ambient concentration, and gas-particle partitioning on the efficacy of the use of nitromonoaromatics, benzene dicarboxylic acids, furandiones, and DHOPA as tracers for SOA from anthropogenic VOCs. First and foremost, DHOPA was detected consistently and only in particle phase and is specific to toluene photooxidation, making it a good tracer for toluene SOA despite its relatively low concentrations. Second, $\mathrm{PhA}$ is the most abundant benzene dicarboxylic acid isomer and correlates highly with DHOPA. Similarly, 4M-PhA correlates highly with DHOPA. Although the measured $F_{\mathrm{p}}$ values suggest partitioning to the gas phase for these two species, this is likely due to instrumental interferences from the corresponding anhydrides. Their particlephase concentration, nonetheless, are expected to be useful in tracing naphthalene-derived SOA. Third, $4 \mathrm{H}-3 \mathrm{NB}$ was detected only in the particle phase and found to be specific to toluene photooxidation at low levels of $\mathrm{NO}_{x}$. Because of their unique sources, detectability, and partitioning towards the particle phase, these species are expected to pro- vide much needed insight to SOA from anthropogenic origins, which can support a better understanding of the sources of atmospheric aerosols.

While the above-described species are proposed as tracers of anthropogenic SOA, structurally similar compounds are largely associated with primary sources and are not suitable tracers of SOA. For example, t-PhA, 4NC, 4M-5NC, and 5NSA were highly correlated with levoglucosan and known to be biomass burning products. Other species such as furandiones hold significant potential to be used as an indicator of processed aromatic VOCs in the atmosphere due to their source specificity but are not recommended as SOA tracers because of their substantial partitioning in the gas phase and water sensitivity. These findings underscore the importance of evaluating and quantifying potential SOA tracers on an individual species level, as some species within a compound class may provide source specificity, while others do not. Given the limited time and geographic distribution for the samples analysed in this study, further investigation is needed to realize the value of these compounds as tracers of anthropogenic SOA more broadly.

\section{Data availability}

All ambient measurements used in this paper are available as Supplemental data.

\section{The Supplement related to this article is available online at doi:10.5194/acp-17-2053-2017-supplement.}

Competing interests. The authors declare that they have no conflict of interest.

Acknowledgements. This work was supported by the National Science Foundation (NSF) through AGS grant number 1405014. We thank Carter Madler and Candice Smith for their assistance in the laboratory preparations, and Md. Robiul Islam for help with sample collection.

Edited by: J. Roberts

Reviewed by: two anonymous referees

\section{References}

Al-Naiema, I., Estillore, A. D., Mudunkotuwa, I. A., Grassian, V. H., and Stone, E. A.: Impacts of co-firing biomass on emissions of particulate matter to the atmosphere, Fuel, 162, 111120, doi:10.1016/j.fuel.2015.08.054, 2015. 
Al-Naiema, I. M., Roppo, H. M., and Stone, E. A.: Quantification of furandiones in ambient aerosol, Atmos. Environ., 153, 41-46, doi:10.1016/j.atmosenv.2017.01.002, 2017.

Bandow, H., Washida, N., and Akimoto, H.: Ring-cleavage reactions of aromatic-hydrocarbons studied by FTIR spectroscopy: Photooxidation of toluene and benzene in the nox-air system, Bull. Chem. Soc. Jpn., 58, 2531-2540, doi:10.1246/bcsj.58.2531, 1985.

Chan, A. W. H., Kautzman, K. E., Chhabra, P. S., Surratt, J. D., Chan, M. N., Crounse, J. D., Kürten, A., Wennberg, P. O., Flagan, R. C., and Seinfeld, J. H.: Secondary organic aerosol formation from photooxidation of naphthalene and alkylnaphthalenes: implications for oxidation of intermediate volatility organic compounds (IVOCs), Atmos. Chem. Phys., 9, 3049-3060, doi:10.5194/acp-9-3049-2009, 2009.

Chuang, J. C., Hannan, S. W., and Wilson, N. K.: Field comparison of polyurethane foam and XAD-2 resin for air sampling for polynuclear aromatic-hydrocarbons, Environ. Sci. Technol., 21, 798-804, doi:10.1021/es00162a011, 1987.

Claeys, M., Graham, B., Vas, G., Wang, W., Vermeylen, R., Pashynska, V., Cafmeyer, J., Guyon, P., Andreae, M. O., Artaxo, P., and Maenhaut, W.: Formation of secondary organic aerosols through photooxidation of isoprene, Science, 303, 1173-1176, doi:10.1126/science.1092805, 2004a.

Claeys, M., Wang, W., Ion, A. C., Kourtchev, I., Gelencser, A., and Maenhaut, W.: Formation of secondary organic aerosols from isoprene and its gas-phase oxidation products through reaction with hydrogen peroxide, Atmos. Environ., 38, 4093-4098, doi:10.1016/j.atmosenv.2004.06.001, 2004b.

Dachs, J. and Eisenreich, S. J.: Adsorption onto aerosol soot carbon dominates gas-particle partitioning of polycyclic aromatic hydrocarbons, Environ. Sci. Technol., 34, 3690-3697, doi:10.1021/es991201+, 2000.

Delgado-Saborit, J. M., Stark, C., and Harrison, R. M.: Use of a versatile high efficiency multiparallel denuder for the sampling of pahs in ambient air: Gas and particle phase concentrations, particle size distribution and artifact formation, Environ. Sci. Technol., 48, 499-507, doi:10.1021/es402937d, 2014.

Ding, X., Wang, X.-M., Gao, B., Fu, X.-X., He, Q.-F., Zhao, X.-Y., Yu, J.-Z., and Zheng, M.: Tracer-based estimation of secondary organic carbon in the Pearl River Delta, south China, J. Geophys. Res.-Atmos., 117, D05313, doi:10.1029/2011jd016596, 2012.

Donahue, N. M., Robinson, A. L., Stanier, C. O., and Pandis, S. N.: Coupled partitioning, dilution, and chemical aging of semivolatile organics, Environ. Sci. Technol., 40, 2635-2643, doi:10.1021/es052297c, 2006.

Dron, J., Abidi, E., El Haddad, I., Marchand, N., and Wortham, H.: Precursor ion scanning-mass spectrometry for the determination of nitro functional groups in atmospheric particulate organic matter, Anal. Chim. Acta, 618, 184-195, doi:10.1016/j.aca.2008.04.057, 2008.

EPA: Estimation Programs Interface Suite ${ }^{\mathrm{TM}}$ for Microsoft ${ }^{\circledR}$ Windows, v 4.11 or insert version used, United States Environmental Protection Agency, Washington, DC, USA, 2012.

Fang, W., Gong, L., Shan, X., Liu, F., Wang, Z., and Sheng, L.: Thermal desorption/tunable vacuum-ultraviolet time-of-flight photoionization aerosol mass spectrometry for investigating secondary organic aerosols in chamber experiments, Anal. Chem., 83, 9024-9032, doi:10.1021/ac201838e, 2011.
Forstner, H. J. L., Flagan, R. C., and Seinfeld, J. H.: Secondary organic aerosol from the photooxidation of aromatic hydrocarbons: Molecular composition, Environ. Sci. Technol., 31, 1345-1358, doi:10.1021/es9605376, 1997.

Fraser, M. P., Cass, G. R., and Simoneit, B. R. T.: Air quality model evaluation data for organics. 6. C-3-C-24 organic acids, Environ. Sci. Technol., 37, 446-453, doi:10.1021/es0209262, 2003.

Fu, T. M., Jacob, D. J., Wittrock, F., Burrows, J. P., Vrekoussis, M., and Henze, D. K.: Global budgets of atmospheric glyoxal and methylglyoxal, and implications for formation of secondary organic aerosols, J. Geophys. Res.-Atmos., 113, D15303, doi:10.1029/2007jd009505, 2008.

Hallquist, M., Wenger, J. C., Baltensperger, U., Rudich, Y., Simpson, D., Claeys, M., Dommen, J., Donahue, N. M., George, C., Goldstein, A. H., Hamilton, J. F., Herrmann, H., Hoffmann, T., Iinuma, Y., Jang, M., Jenkin, M. E., Jimenez, J. L., Kiendler-Scharr, A., Maenhaut, W., McFiggans, G., Mentel, Th. F., Monod, A., Prévôt, A. S. H., Seinfeld, J. H., Surratt, J. D., Szmigielski, R., and Wildt, J.: The formation, properties and impact of secondary organic aerosol: current and emerging issues, Atmos. Chem. Phys., 9, 5155-5236, doi:10.5194/acp-9-51552009, 2009.

Hamilton, J. F., Lewis, A. C., Bloss, C., Wagner, V., Henderson, A. P., Golding, B. T., Wirtz, K., Martin-Reviejo, M., and Pilling, M. J.: Measurements of photo-oxidation products from the reaction of a series of alkyl-benzenes with hydroxyl radicals during EXACT using comprehensive gas chromatography, Atmos. Chem. Phys., 3, 1999-2014, doi:10.5194/acp-3-1999-2003, 2003.

Hamilton, J. F., Webb, P. J., Lewis, A. C., and Reviejo, M. M.: Quantifying small molecules in secondary organic aerosol formed during the photo-oxidation of toluene with hydroxyl radicals, Atmos. Environ., 39, 7263-7275, doi:10.1016/j.atmosenv.2005.09.006, 2005.

Harrison, M. A. J., Barra, S., Borghesi, D., Vione, D., Arsene, C., and Olariu, R. L.: Nitrated phenols in the atmosphere: a review, Atmos. Environ., 39, 231-248, doi:10.1016/j.atmosenv.2004.09.044, 2005.

Hawthorne, S. B., Krieger, M. S., Miller, D. J., and Mathiason, M. B.: Collection and quantitation of methoxylated phenol tracers for atmospheric-pollution from residential wood stoves, Environ. Sci. Technol., 23, 470-475, doi:10.1021/es00181a013, 1989.

He, J. and Balasubramanian, R.: A study of gas/particle partitioning of SVOCs in the tropical atmosphere of Southeast Asia, Atmos. Environ., 43, 4375-4383, doi:10.1016/j.atmosenv.2009.03.055, 2009.

Heald, C. L., Jacob, D. J., Park, R. J., Russell, L. M., Huebert, B. J., Seinfeld, J. H., Liao, H., and Weber, R. J.: A large organic aerosol source in the free troposphere missing from current models, Geophys. Res. Lett., 32, L18809, doi:10.1029/2005g1023831, 2005.

Henze, D. K., Seinfeld, J. H., Ng, N. L., Kroll, J. H., Fu, T.-M., Jacob, D. J., and Heald, C. L.: Global modeling of secondary organic aerosol formation from aromatic hydrocarbons: highvs. low-yield pathways, Atmos. Chem. Phys., 8, 2405-2420, doi:10.5194/acp-8-2405-2008, 2008.

Hu, D., Bian, Q., Li, T. W. Y., Lau, A. K. H., and Yu, J. Z.: Contributions of isoprene, monoterpenes, beta-caryophyllene, and toluene to secondary organic aerosols in Hong Kong during the summer of 2006, J. Geophys. Res.-Atmos., 113, D22206, doi:10.1029/2008jd010437, 2008. 
Iinuma, Y., Brueggemann, E., Gnauk, T., Mueller, K., Andreae, M. O., Helas, G., Parmar, R., and Herrmann, H.: Source characterization of biomass burning particles: The combustion of selected European conifers, African hardwood, savanna grass, and German and Indonesian peat, J. Geophys. Res.-Atmos., 112, D08209, doi:10.1029/2006jd007120, 2007.

Iinuma, Y., Boege, O., Graefe, R., and Herrmann, H.: Methylnitrocatechols: Atmospheric tracer compounds for biomass burning secondary organic aerosols, Environ. Sci. Technol., 44, 8453-8459, doi:10.1021/es102938a, 2010.

Irei, S., Rudolph, J., Huang, L., Auld, J., Collin, F., and Hastie, D.: Laboratory studies of carbon kinetic isotope effects on the production mechanism of particulate phenolic compounds formed by toluene photooxidation: A tool to constrain reaction pathways, J. Phys. Chem. A, 119, 5-13, doi:10.1021/jp5104609, 2015.

Jang, M. S. and Kamens, R. M.: Characterization of secondary aerosol from the photooxidation of toluene in the presence of $\mathrm{NO}_{x}$ and 1-propene, Environ. Sci. Technol., 35, 3626-3639, doi:10.1021/es010676+, 2001.

Jayarathne, T., Rathnayake, C. M., and Stone, E. A.: Local source impacts on primary and secondary aerosols in the Midwestern United States, Atmos. Environ., 130, 74-83, doi:10.1016/j.atmosenv.2015.09.058, 2016.

Kahnt, A., Behrouzi, S., Vermeylen, R., Shalamzari, M. S., Vercauteren, J., Roekens, E., Claeys, M., and Maenhaut, W.: Oneyear study of nitro-organic compounds and their relation to wood burning in $\mathrm{PM}_{10}$ aerosol from a rural site in Belgium, Atmos. Environ., 81, 561-568, doi:10.1016/j.atmosenv.2013.09.041, 2013.

Kautzman, K. E., Surratt, J. D., Chan, M. N., Chan, A. W. H., Hersey, S. P., Chhabra, P. S., Dalleska, N. F., Wennberg, P. O., Flagan, R. C., and Seinfeld, J. H.: Chemical Composition of Gas- and Aerosol-Phase Products from the Photooxidation of Naphthalene, J. Phys. Chem. A, 114, 913-934, doi:10.1021/jp908530s, 2010.

Kawamura, K. and Kaplan, I. R.: Motor exhaust emissions as a primary source for dicarboxylic-acids in los-angeles ambient air, Environ. Sci. Technol., 21, 105-110, doi:10.1021/es00155a014, 1987.

Kim, Y.-H. and Kim, K.-H.: A simple methodological validation of the gas/particle fractionation of polycyclic aromatic hydrocarbons in ambient air, Scientific Reports, 5, 11679, doi:10.1038/srep11679, 2015.

Kitanovski, Z., Grgic, I., Vermeylen, R., Claeys, M., and Maenhaut, W.: Liquid chromatography tandem mass spectrometry method for characterization of monoaromatic nitro-compounds in atmospheric particulate matter, J. Chromatogr. A, 1268, 35-43, doi:10.1016/j.chroma.2012.10.021, 2012.

Kleindienst, T. E., Conver, T. S., McIver, C. D., and Edney, E. O.: Determination of secondary organic aerosol products from the photooxidation of toluene and their implications in ambient $\mathrm{PM}_{2.5}$, J. Atmos. Chem., 47, 79-100, doi:10.1023/b:joch.0000012305.94498.28, 2004.

Kleindienst, T. E., Jaoui, M., Lewandowski, M., Offenberg, J. H., Lewis, C. W., Bhave, P. V., and Edney, E. O.: Estimates of the contributions of biogenic and anthropogenic hydrocarbons to secondary organic aerosol at a southeastern US location, Atmos. Environ., 41, 8288-8300, doi:10.1016/j.atmosenv.2007.06.045, 2007.
Kleindienst, T. E., Jaoui, M., Lewandowski, M., Offenberg, J. H., and Docherty, K. S.: The formation of SOA and chemical tracer compounds from the photooxidation of naphthalene and its methyl analogs in the presence and absence of nitrogen oxides, Atmos. Chem. Phys., 12, 8711-8726, doi:10.5194/acp-12-87112012, 2012.

Koehler, C. A., Fillo, J. D., Ries, K. A., Sanchez, J. T., and De Haan, D. O.: Formation of secondary organic aerosol by reactive condensation of furandiones, aldehydes, and water vapor onto inorganic aerosol seed particles, Environ. Sci. Technol., 38, 50645072, doi:10.1021/es034672b, 2004.

Kroll, J. H. and Seinfeld, J. H.: Chemistry of secondary organic aerosol: Formation and evolution of low-volatility organics in the atmosphere, Atmos. Environ., 42, 3593-3624, doi:10.1016/j.atmosenv.2008.01.003, 2008.

Lewandowski, M., Jaoui, M., Offenberg, J. H., Kleindienst, T. E., Edney, E. O., Sheesley, R. J., and Schauer, J. J.: Primary and secondary contributions to ambient PM in the midwestern United States, Environ. Sci. Technol., 42, 3303-3309, doi:10.1021/es0720412, 2008.

Lin, P., Liu, J., Shilling, J. E., Kathmann, S. M., Laskin, J., and Laskin, A.: Molecular characterization of brown carbon $(\mathrm{BrC})$ chromophores in secondary organic aerosol generated from photo-oxidation of toluene, Phys. Chem. Chem. Phys., 17, 23312-23325, doi:10.1039/c5cp02563j, 2015.

Ma, W.-L., Sun, D.-Z., Shen, W.-G., Yang, M., Qi, H., Liu, L.Y., Shen, J.-M., and Li, Y.-F.: Atmospheric concentrations, sources and gas-particle partitioning of PAHs in Beijing after the 29th Olympic Games, Environ. Pollut., 159, 1794-1801, doi:10.1016/j.envpol.2011.03.025, 2011.

Matsui, H., Koike, M., Takegawa, N., Kondo, Y., Griffin, R. J., Miyazaki, Y., Yokouchi, Y., and Ohara, T.: Secondary organic aerosol formation in urban air: Temporal variations and possible contributions from unidentified hydrocarbons, J. Geophys. Res.Atmos., 114, D04201, doi:10.1029/2008jd010164, 2009.

Mirivel, G., Riffault, V., and Galloo, J.-C.: Analysis of phthalic, isophthalic and long-chain (C-4-C-12) dicarboxylic acids in atmospheric aerosols by UPLC/ESI/ToF-MS, Analytical Methods, 3, 1172-1179, doi:10.1039/c0ay00677g, 2011.

Mkoma, S. L. and Kawamura, K.: Molecular composition of dicarboxylic acids, ketocarboxylic acids, a-dicarbonyls and fatty acids in atmospheric aerosols from Tanzania, East Africa during wet and dry seasons, Atmos. Chem. Phys., 13, 2235-2251, doi:10.5194/acp-13-2235-2013, 2013.

Mukaka, M. M.: Statistics Corner: A guide to appropriate use of Correlation coefficient in medical research, Malawi Med. J., 24, 69-71, 2012.

Ng, N. L., Kroll, J. H., Chan, A. W. H., Chhabra, P. S., Flagan, R. C., and Seinfeld, J. H.: Secondary organic aerosol formation from m-xylene, toluene, and benzene, Atmos. Chem. Phys., 7, 3909-3922, doi:10.5194/acp-7-3909-2007, 2007.

Oanh, N. T. K., Reutergardh, L. B., and Dung, N. T.: Emission of polycyclic aromatic hydrocarbons and particulate matter from domestic combustion of selected fuels, Environ. Sci. Technol., 33, 2703-2709, 1999.

OSHA: Phthalic Anhydride, Organic Methods Evaluation Branch. OSHA Salt Lake Technical Center, Salt Lake City, UT 84165 , 1991. 
Pankow, J. F.: An absorption-model of the gas aerosol partitioning involved in the formation of secondary organic aerosol, Atmos. Environ., 28, 189-193, doi:10.1016/1352-2310(94)900949, 1994.

Pankow, J. F., Storey, J. M. E., and Yamasaki, H.: Effects of relativehumidity on gas-particle partitioning of semivolatile organiccompounds to urban particulate matter, Environ. Sci. Technol., 27, 2220-2226, doi:10.1021/es00047a032, 1993.

Peng, J., Li, M., Zhang, P., Gong, S., Zhong, M., Wu, M., Zheng, M., Chen, C., Wang, H., and Lou, S.: Investigation of the sources and seasonal variations of secondary organic aerosols in $\mathrm{PM}_{2.5}$ in Shanghai with organic tracers, Atmos. Environ., 79, 614-622, doi:10.1016/j.atmosenv.2013.07.022, 2013.

Possanzini, M., Di Palo, V., Gigliucci, P., Concetta, M., Sciano, T., and Cecinato, A.: Determination of phase-distributed PAH in Rome ambient air by denuder/GC-MS method, Atmos. Environ., 38, 1727-1734, doi:10.1016/j.atmosenv.2003.12.024, 2004.

Robinson, A. L., Donahue, N. M., Shrivastava, M. K., Weitkamp, E. A., Sage, A. M., Grieshop, A. P., Lane, T. E., Pierce, J. R., and Pandis, S. N.: Rethinking organic aerosols: Semivolatile emissions and photochemical aging, Science, 315, 1259-1262, doi:10.1126/science.1133061, 2007.

Rogge, W. F., Ondov, J. M., Bernardo-Bricker, A., and Sevimoglu, O.: Baltimore $\mathrm{PM}_{2.5}$ Supersite: highly time-resolved organic compounds-sampling duration and phase distributionimplications for health effects studies, Anal. Bioanal. Chem., 401, 3069-3082, doi:10.1007/s00216-011-5454-9, 2011.

Sato, K., Hatakeyama, S., and Imamura, T.: Secondary organic aerosol formation during the photooxidation of toluene: $\mathrm{NO}_{x}$ dependence of chemical composition, J. Phys. Chem. A, 111, 9796-9808, doi:10.1021/jp071419f, 2007.

Sato, K., Takami, A., Kato, Y., Seta, T., Fujitani, Y., Hikida, T., Shimono, A., and Imamura, T.: AMS and LC/MS analyses of SOA from the photooxidation of benzene and 1,3,5-trimethylbenzene in the presence of $\mathrm{NO}_{x}$ : effects of chemical structure on SOA aging, Atmos. Chem. Phys., 12, 4667-4682, doi:10.5194/acp-124667-2012, 2012.

Schauer, J. J., Rogge, W. F., Hildemann, L. M., Mazurek, M. A., Cass, G. R., and Simoneit, B. R. T.: Source apportionment of airborne particulate matter using organic compounds as tracers, Atmos. Environ., 30, 3837-3855, doi:10.1016/13522310(96)00085-4, 1996.

Schauer, J. J., Kleeman, M. J., Cass, G. R., and Simoneit, B. R. T.: Measurement of emissions from air pollution sources. 2. C-1 through C-30 organic compounds from medium duty diesel trucks, Environ. Sci. Technol., 33, 1578-1587, doi:10.1021/es980081n, 1999.

Schauer, J. J., Mader, B. T., Deminter, J. T., Heidemann, G., Bae, M. S., Seinfeld, J. H., Flagan, R. C., Cary, R. A., Smith, D., Huebert, B. J., Bertram, T., Howell, S., Kline, J. T., Quinn, P., Bates, T., Turpin, B., Lim, H. J., Yu, J. Z., Yang, H., and Keywood, M. D.: ACE-Asia intercomparison of a thermal-optical method for the determination of particle-phase organic and elemental carbon, Environ. Sci. Technol., 37, 993-1001, doi:10.1021/es020622f, 2003.

Shen, R.-Q., Ding, X., He, Q.-F., Cong, Z.-Y., Yu, Q.-Q., and Wang, X.-M.: Seasonal variation of secondary organic aerosol tracers in Central Tibetan Plateau, Atmos. Chem. Phys., 15, 8781-8793, doi:10.5194/acp-15-8781-2015, 2015.
Simoneit, B. R. T., Schauer, J. J., Nolte, C. G., Oros, D. R., Elias, V. O., Fraser, M. P., Rogge, W. F., and Cass, G. R.: Levoglucosan, a tracer for cellulose in biomass burning and atmospheric particles, Atmos. Environ., 33, 173-182, doi:10.1016/s13522310(98)00145-9, 1999.

Terzi, E. and Samara, C.: Gas-particle partitioning of polycyclic aromatic hydrocarbons in urban, adjacent coastal, and continental background sites of western Greece, Environ. Sci. Technol., 38, 4973-4978, doi:10.1021/es040042d, 2004.

Tremp, J., Mattrel, P., Fingler, S., and Giger, W.: Phenols and nitrophenols as tropospheric pollutants - emissions from automobile exhausts and phase-transfer in the atmosphere, Water Air Soil Poll., 68, 113-123, doi:10.1007/bf00479396, 1993.

Trivedi, B. C., and Culbertson, B. M.: Maleic Anhydride, Springer Science+Business Media, New York, 1982.

Volkamer, R., Jimenez, J. L., San Martini, F., Dzepina, K., Zhang, Q., Salcedo, D., Molina, L. T., Worsnop, D. R., and Molina, M. J.: Secondary organic aerosol formation from anthropogenic air pollution: Rapid and higher than expected, Geophys. Res. Lett., 33, L17811, doi:10.1029/2006g1026899, 2006.

Wang, W., Simonich, S. L. M., Wang, W., Giri, B., Zhao, J., Xue, M., Cao, J., Lu, X., and Tao, S.: Atmospheric polycyclic aromatic hydrocarbon concentrations and gas/particle partitioning at background, rural village and urban sites in the North China Plain, Atmos. Res., 99, 197-206, doi:10.1016/j.atmosres.2010.10.002, 2011.

Williams, B. J., Goldstein, A. H., Kreisberg, N. M., and Hering, S. V.: In situ measurements of gas/particle-phase transitions for atmospheric semivolatile organic compounds, Proc. Natl. Acad. Sci. USA, 107, 6676-6681, doi:10.1073/pnas.0911858107, 2010.

Yamasaki, H., Kuwata, K., and Miyamoto, H.: Effects of ambient-temperature on aspects of airborne polycyclic aromatic-hydrocarbons, Environ. Sci. Technol., 16, 189-194, doi:10.1021/es00098a003, 1982.

Yatavelli, R. L. N., Stark, H., Thompson, S. L., Kimmel, J. R., Cubison, M. J., Day, D. A., Campuzano-Jost, P., Palm, B. B., Hodzic, A., Thornton, J. A., Jayne, J. T., Worsnop, D. R., and Jimenez, J. L.: Semicontinuous measurements of gas-particle partitioning of organic acids in a ponderosa pine forest using a MOVI-HRToFCIMS, Atmos. Chem. Phys., 14, 1527-1546, doi:10.5194/acp14-1527-2014, 2014.

Yu, J. Z., Cocker, D. R., Griffin, R. J., Flagan, R. C., and Seinfeld, J. H.: Gas-phase ozone oxidation of monoterpenes: Gaseous and particulate products, J. Atmos. Chem., 34, 207-258, doi:10.1023/a:1006254930583, 1999.

Zhang, X., Lin, Y.-H., Surratt, J. D., and Weber, R. J.: Sources, composition and absorption angstrom exponent of light-absorbing organic components in aerosol extracts from the los angeles basin, Environ. Sci. Technol., 47, 3685-3693, doi:10.1021/es305047b, 2013. 